\title{
SEDIMENTATION ANALYSIS BURNED FOREST LAND AT TAHURA R.SOERJO LEDUG BLOCK
}

\author{
Yonny Fathurizky ${ }^{1)}$, Tatag Muttaqin ${ }^{2)}$, Nugroho Tri Waskito ${ }^{3)}$ \\ ${ }^{1)}$ Forestry Department, Faculty of Agriculture-Animal Husbandry, University of Muhammadiyah Malang \\ Tlogomas Street Number. 246, Malang City, East Java Province 65144 \\ *Email: yonny9792@gmail.com
}

\begin{abstract}
The most of forest destruction is caused by fire, which is in a short time fire could reach a large amount of land. Forest fires have more negative impacts than positive impacts on soil properties and especially on erosion. This research was conducted to determine the amount of sedimentation, and to determine the relationship between rainfall and sedimentation that occured at TAHURA R.Soerjo Ledug Block. This research was conducted in December 2018 at TAHURA R.Soerjo, with an estimated altitude of 1100-1200 mdpl. There were 13 rainfall events in December 2018. The highest rainfall was $68,2 \mathrm{~mm}$, and the lowest rainfall was 2,5 $\mathrm{mm}$. The largest amount of sediment is $0,94 \mathrm{~kg} / \mathrm{ha}$, and the smallest amount of sediment is $0,29 \mathrm{~kg} / \mathrm{ha}$, and the average amount of sediment is $0,48 \mathrm{~kg} / \mathrm{ha}$. The low value of sediment obtained is caused by the good quality of the soil on the area, and is also caused by the vegetation and it dominated by the weeds.

Keywords : Sedimentation, Burned land.
\end{abstract}

\section{INTISARI}

Kebakaran merupakan penyebab kerusakan hutan yang paling besar, yang mana dalam waktu singkat dapat menghancurkan kawasan yang cukup luas. Kebakaran hutan ternyata lebih banyak menimbulkan dampak negatif daripada dampak positif terhadap sifat-sifat tanah dan terutama terhadap erosi. Penelitian ini dilaksanakan untuk mengetahui besarnya sedimentasi, dan mengetahui hubungan antara curah hujan dengan sedimentasi yang terjadi pada kawasan bekas kebakaran hutan TAHURA R.Soerjo Blok Ledug. Penelitian ini dilaksanakan pada bulan Desember 2018 di Kawasan bekas kebakaran hutan TAHURA R.Soerjo, dengan estimasi ketinggian 1100-1200 mdpl. Terdapat 13 kejadian hujan pada bulan Desember 2018. Curah hujan tertinggi $68,2 \mathrm{~mm}$, dan curah hujan terrendah 2,5mm. Nilai muatan sedimen terbesar yaitu $0,94 \mathrm{~kg} / \mathrm{ha}$, serta nilai muatan sedimen terkecil yaitu 0,29 $\mathrm{kg} / \mathrm{ha}$, dan nilai muatan sedimen rata-ratanya yaitu $0,48 \mathrm{~kg} / \mathrm{ha}$ rendahnya nilai sedimen yang didapatkan dipengaruhi oleh baiknya kualitas tanah pada lahan tersebut, dan juga dipengaruhi oleh keadaan vegetasi yang rapat dan di dominasi oleh ilalang.

Kata kunci: Sedimentasi, Lahan Bekas Kebakaran. 


\section{JOURNAL OF FOREST SCIENCE AVICENNIA}

E-ISSN : 2622-8505 | Email : avicennia kehutananummaumm.ac id http//cjournal umm ac.it/index.php/avicennia

O Jl. Raya Tlogomas No.246 Malang Jawa Timur (O) 0822-5785-2386 (Febri)

\section{Pendahuluan}

Menurut Undang-Undang No.41 tahun 1999, hutan adalah suatu kesatuan ekosistem berupa hamparan lahan berisi sumber daya alam hayati yang didominasi pepohonan dalam persekutuan alam lingkungannya, yang satu dengan lainnya tidak dapat dipisahkan. Hutan adalah hal yang penting bagi umat manusia, sebagai penghasil oksigen dan penyedia sumberdaya hayati yang ada di dalamnya, salah satu contohnya yaitu Tahura R.Soerjo. Tahura R.Soerjo memiliki fungsi sebagai kawasan pelestarian alam, dimana segala hal yang ada di dalamnya di lindungi oleh undang-undang. Sebagai manusia sudah selayaknya bagi kita agar turut menjaga kelestarian hutan agar manfaat yang didapatkan dari adanya hutan dapat dirasakan oleh generasi penerus kita nanti.

Pada tahun 2015 lalu, kebakaran hutan melanda Tahura R.Soerjo yang terjadi di beberapa titik. Kebakaran ini menyebabkan hancurnya kawasan yang terdampak oleh api tersebut. Menurut (Hatta 2009, dalam Murtinah, Edwin and Bane, 2017) kebakaran merupakan penyebab kerusakan hutan yang paling besar, yang mana dalam waktu singkat dapat menghancurkan kawasan yang cukup luas. Kebakaran hutan ternyata lebih banyak menimbulkan dampak negatif daripada dampak positif terhadap sifatsifat tanah dan terutama terhadap erosi.

Dampak yang ditimbulkan dari kebakaran hutan ini menyebabkan kawasan tersebut kehilangan fungsinya sebagai penyedia oksigen dan fungsi konservasi tanah dan air. Kebakaran hutan ini tidak hanya mengancam kualitas lahan yang ada pada daerah yang terdampak, tetapi juga mengancam sumber air yang ada di sekitar titik kebakaran. Kebakaran yang terjadi di Tahura R.Soerjo ini salah satunya terjadi di blok Ledug, Prigen.

\section{Metode Penelitian}

Penelitian ini dilaksanakan pada bulan Desember 2018 dan bertempat di lahan bekas kebakaran hutan Taman Hutan Raya (TAHURA) R.Soerjo blok Ledug Prigen.

Alat yang digunakan dalam penelitian ini yaitu laptop, kamera, botol bekas, jerigen, corong, selang, bambu penyangga, gelas ukur, penggaris, ombrometer, SPAS, Automatic Water Level Recorder (AWLR), bola pingpong, stopwatch, cetok, dan double ring. Bahan yang digunakan dalam penelitian ini yaitu air hujan, tanah, dan peta kawasan TAHURA. Penelitian yang dilakukan ini menggunakan dua jenis data yang diambil, yaitu data primer dan data sekunder. Data primer yaitu data yang akan kita peroleh dari lapang. Data sekunder yaitu data yang tidak didapat di lapang, seperti karakteristik tanah, bahan organik tanah, dan tekstur tanah.

Menurut (Muttaqin, 2018) pengukuran berat suspensi didapatkan dengan cara, menimbang sampel suspensi yang sudah dioven, lalu dapat dihitung berat suspensinya sebagai berikut:

Berat suspensi $=g 2-g 1$

Keterangan :

$\mathrm{g} 1$ = berat filter kosong $(\mathrm{g})$

$\mathrm{g} 2$ = berat filter berisi suspensi $(\mathrm{g})$ 


\section{JOURNAL OF FOREST SCIENCE AVICENNIA}

E-ISSN : 2622-8505 | Email : avicennia kehutananummaumm.ac id http//cjournal umm ac.it/index.php/avicennia

P.J. Raya Tlogomas No.246 Malang, Jawa Timur (2) 0822-5785-2386 (Febri)

Adapun langkah untuk menghitung besarnya konsentrasi suspensi adalah sebagai berikut :

$$
\mathrm{Csn}=\frac{g 2-g 1}{\text { volume air sample }}
$$

Keterangan :

Csn $=$ Konsentrasi suspensi $(\mathrm{Kg} / \mathrm{m} 3$ atau $\mathrm{g} / \mathrm{L})$

g1 = Berat awal kertas saring ( $\mathrm{g}$ )

g2 = Berat kertas yang terisi suspensi $(\mathrm{g})$

Debit suspensi dapat ditemukan dengan persamaan:

$Q s=Q \times C s$

Keterangan :

Qs = Debit suspensi ( $\mathrm{kg} /$ hari)

$\mathrm{Q}=$ Debit aliran $(\mathrm{m} 3 / \mathrm{s})$

$\mathrm{Cs}=$ Konsentrasi suspensi untuk tiap catchment $(\mathrm{kg} / \mathrm{m} 3)$

Setelah memperoleh nilai debit suspensi, kemudian membuat grafik hubungan antara Qs dengan Q, dimana grafik ini nantinya bernama lengkung suspensi dengan menggunakan persamaan:

$$
Q s=a(Q)^{b}
$$

Keterangan :

Qs = Debit suspensi $(\mathrm{kg} / \mathrm{hari})$

$\mathrm{Q}=$ Debit aliran (m3/s)

$a \cdot b=$ Konstanta

\section{Hasil dan Pembahasan Hidrograf Aliran}

Hasil dari pengamatan yang telah dilakukan Ditemukan sebanyak 13 kejadian hujan pada bulan Desember tahun 2018, dimana curah hujan ter-rendah yaitu 2,5 $\mathrm{mm}$ yang terjadi pada tanggal 8 Desember 2018, dan curah hujan tertinggi terjadi pada tanggal 11 Desember 2018 dengan curah hujan 68,2 mm. Kejadian hujan terlama yang terjadi yaitu selama 1 Jam 20 menit. Dari 13 kejadian hujan didapatkan 13 hidrograf aliran yang menjadi dasar perhitungan untuk mendapatkan grafik lengkung aliran dan lengkung suspensi. Nilai hidrograf aliran didapatkan berdasarkan data tinggi muka air, dan curah hujan yang melewati spas dan terekam oleh alat Automatic Water Level Recorder (AWLR), alat AWLR merekam setiap 5 menit sehingga didapatkan data hidrograf aliran.

\section{Analisis sampel tanah}

Tabel 1. Tabel Uji Laboratorium Sampel

\begin{tabular}{|c|c|c|c|c|c|c|}
\hline \multirow[t]{3}{*}{ Kode } & \multirow[t]{2}{*}{$\mathrm{KHJ}$} & \multirow[t]{3}{*}{ Struktur } & \multicolumn{3}{|l|}{$\%$} & \multirow{3}{*}{$\begin{array}{l}\text { Kelas } \\
\text { tekstur }\end{array}$} \\
\hline & & & \multirow[t]{2}{*}{ Pasir } & \multirow[t]{2}{*}{ Debu } & \multirow[t]{2}{*}{ Liat } & \\
\hline & $\begin{array}{l}\mathrm{Cm} \\
\text { jam }^{-}\end{array}$ & & & & & \\
\hline IF 2 & 47,6 & Granuler & 29 & 55 & 16 & $\begin{array}{l}\text { Lempung } \\
\text { Berdebu }\end{array}$ \\
\hline
\end{tabular}
Tanah fisik

Tabel 2. Tabel Uji Laboratorium Sampel Tanah Kimia

\begin{tabular}{|l|l|l|l|}
\hline $\begin{array}{l}\text { No. } \\
\text { lab }\end{array}$ & Kode & C.organik & Bahan Organik \\
\hline TNH & IF 2 & 8,84 & 15,29 \\
\hline
\end{tabular}

Menurut hasil uji laboratorium sampel tanah fisik yang didapatkan pada areal bekas kebakaran yang telah dikompositkan nilai permeabilitas nya 47,6 $\mathrm{cm} /$ jam berstruktur granuler, dan memiliki kandungan pasir $29 \%$, debu $55 \%$, dan liat $16 \%$, serta memiliki tekstur lempung berdebu. Keadaan tanah ini dipengaruhi oleh keadaan lingkungan tersebut dimana sampel tanah didapatkan dari sampel 


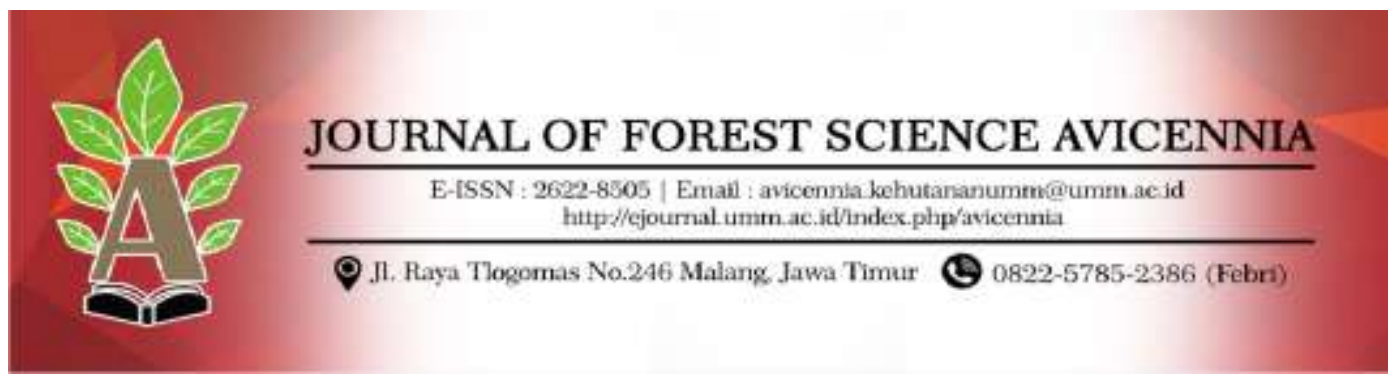

tanah lahan bekas kebakaran. Presentase debu yang tinggi sebesar $55 \%$ tersebut disebabkan karena abu bekas kebakaran yang berubah menjadi debu setelah lapuk dan tercuci oleh air hujan sehingga masuk kedalam pori-pori tanah. Menurut (Murtinah, Edwin and Bane, 2017) nilai rata-rata porositas tanah pada lahan bekas terbakar yaitu 34,99\%, dan pada lahan tidak terbakar yaitu $36,68 \%$. Hasil tersebut menunjukkan bahwa nilai porositas tanah pada lahan bekas terbakar lebih rendah daripada lahan yang tidak terbakar. Hal ini dapat terjadi karena pada tanah bekas terbakar pori-pori tanahnya tertutup oleh abu bekas kebakaran yang tercuci sehingga masuk kedalam pori tanah, menyebabkan ruang pori tanah berkurang dan nilai porositasnya lebih rendah dibandingkan dengan lahan yang tidak terbakar. Bahan organik tanah yang terkandung pada sampel areal bekas kebakaran yaitu sebesar $15,29 \%$.

Berdasarkan hasil tersebut mempengaruhi tanah yang terangkut pada aliran permukaan atau aliran run-off, terbukti bahwa suspensi yang terangkut oleh aliran permukaan nilainya rendah dan dipengaruhi juga oleh keadaan vegetasi yang rapat yang didominasi oleh ilalang yang tinggi, sehingga air yang mengenai lahan tersebut langsung masuk kedalam tanah. Vegetasi dapat mempengaruhi air yang masuk kedalam tanah disebabkan oleh akar-akar yang banyak yang berada dalam tanah, sehingga tanah memiliki banyak ruang, sehingga air dapat masuk dengan leluasa dan mengakibatkan aliran permukaan yang debitnya kecil atau rendah.

\section{Debit Suspensi}

Muatan suspensi didapatkan dari air yang mengangkut hasil erosi dari permukaan ataupun pinggiran sungai. Kadar muatan suspensi yaitu jumlah material suspensi yang terangkut oleh aliran air sungai dalam satuan volume tertentu. Penelitian ini menghitung debit suspensi menggunakan SPAS yang dilengkapi dengan AWLR (Automatic Water Level Recorder). SPAS atau juga bisa disebut dengan $V$ nocth ini dipasang pada lokasi yang dilewati oleh air. Pada kondisi kawasan penelitian ini SPAS dipasang pada curah, dimana curah ini nantinya akan dilewati oleh air yang berasal dari hujan dan akan mengangkut muatan suspensi

Muatan suspensi didapatkan dari air yang mengangkut hasil erosi dari permukaan ataupun pinggiran sungai. Kadar muatan suspensi yaitu jumlah material suspensi yang terangkut oleh aliran air sungai dalam satuan volume tertentu. Pada kondisi kawasan penelitian ini SPAS dipasang pada curah, dimana curah ini nantinya akan dilewati oleh air yang berasal dari hujan dan akan mengangkut muatan suspensi. Untuk mengetahui debit suspensi harus diketahui besar nilai debit aliran yang terjadi. Besarnya nilai debit aliran didapatkan dari persamaan kurva lengkung aliran yang didapatkan sebelumnya. Kurva lengkung aliran didapat berdasarkan pengukuran data debit dari berbagai ketinggian muka air yang mencakup keadaan tinggi muka air rendah hingga tinggi. Berdasarkan hasil yang didapatkan, dapat diketahui bahwa semakin tinggi nilai tinggi muka air maka semakin besar pula nilai debit aliran yang terjadi.

Nilai debit suspensi diperoleh dari perkalian muatan suspensi dengan debit aliran yang diperoleh dari persamaan kurva lengkung aliran. Data debit suspensi kemudian diolah untuk dibuat lengkung 


\section{JOURNAL OF FOREST SCIENCE AVICENNIA}

E-ISSN : 2622-8505 | Email : avicennia kehutananummaumm.acid http//cjournal umm ac.it/index.php/avicennia

O Jl. Raya Tlogomas No.246 Malang Jawa Timur (2) 0822-5785-2386 (Febri)

persamaan hubungan antara debit suspensi dengan debit aliran yang diperoleh di lapangan. Lengkung sedimen melayang adalah grafik yang menggambarkan hubungan antara debit sedimen melayang sesaat dengan debit (Soewarno, 2000). Lengkung suspensi yang didapatkan yaitu: besar nilai variabel $X$ dalam mempengaruhi variabel $Y$. Variabel $X$ dalam persamaan ini yaitu debit aliran, dan variabel $Y$ dalam persamaan ini yaitu debit suspensi. Nilai $R^{2}$ tersebut memiliki arti bahwa debit aliran mempengaruhi debit suspensi sebesar $24,19 \%$ dan sisanya dipengaruhi oleh variabel lain. Persamaan yang diperoleh ini nantinya dapat digunakan untuk menaksir nilai debit suspensi per 5 menit.

\section{Muatan Sedimen}

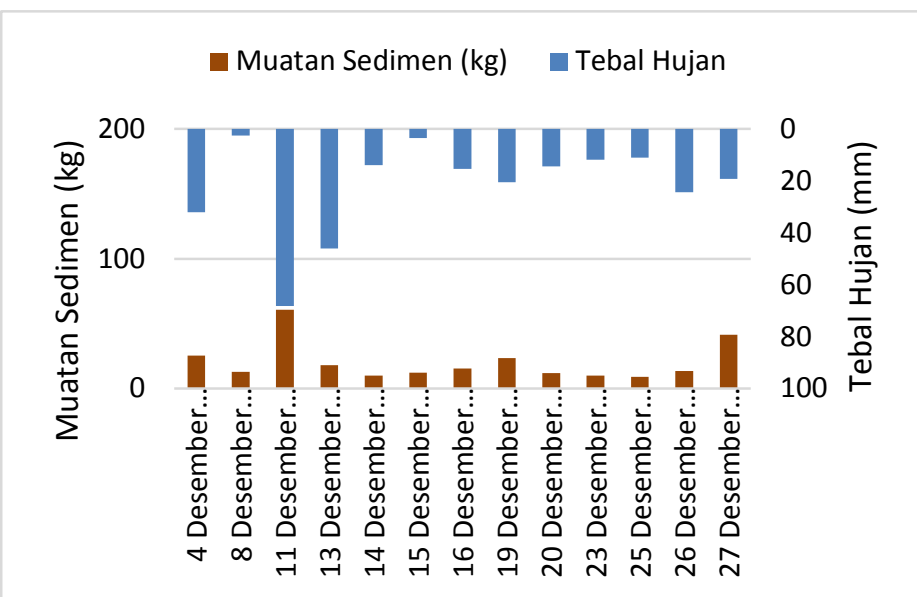

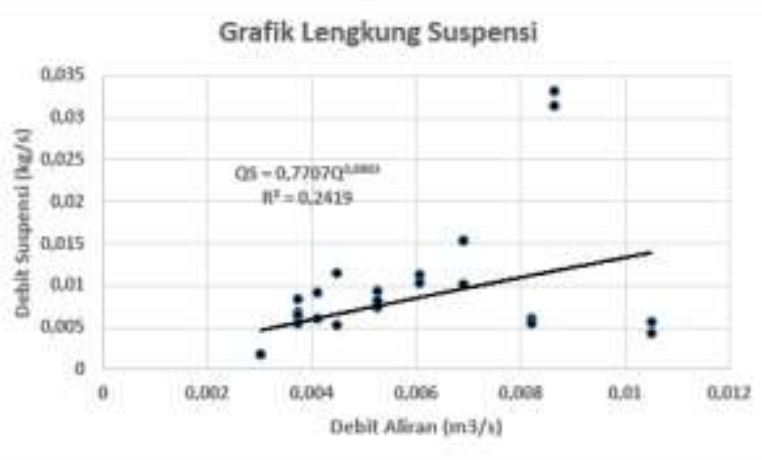

Gambar 1. Grafik Lengkung Suspensi

Berdasarkan grafik diatas diperoleh persamaan QS =0,7707(Q)0,8803 dengaGambar 2. Grafik Nilai Muatan Sedimen nilai $R^{2}=0,2419$ dimana QS yaitu debit suspensi $(\mathrm{kg} / \mathrm{s})$ dan $\mathrm{Q}$ adalah debit aliran (m3/s). Nilai $R^{2}$ menunjukkan seberapa
Nilai muatan sedimen yang didapatkan selama penelitian berlangsung, 


\section{JOURNAL OF FOREST SCIENCE AVICENNIA}

E-ISSN : 2622-8505 | Email : avicennia kehutananumm@umm.ac id http//cjournal umm ac.it/index.php/avicennia

P. R. Raya Tlogomas No.246 Malang Jawa Timur (2) 0822-5785-2386 (Febri)

didapatkan nilai terendah yaitu sebesar $14,34 \mathrm{~kg}$ dan nilai muatan sedimen yang paling tinggi yaitu sebesar 47,22 kg, dari 13 kejadian hujan tersebut didapatkan rata-rata muatan sedimennya yaitu 24,02 kg. Dari grafik diatas dapat dilihat pada 11 Desember dimana curah hujan paling tinggi didapatkan juga muatan sedimen yang besar. Hal ini menunjukkan bahwa curah hujan yang tinggi juga mengangkut muatan sedimen yang banyak sehingga didapatkan endapan atau sedimen yang cukup banyak yaitu sekitar 47,22 kg. Jika hasil tersebut dikonversikan dalam $\mathrm{kg} / \mathrm{ha}$, dalam 1 hektar nilai muatan sedimen tertinggi yang didapatkan yaitu 0,94 $\mathrm{kg} / \mathrm{ha}$. Nilai muatan sedimen terendah yang didapatkan dalam 1 hektar yaitu 0,29 $\mathrm{kg} / \mathrm{ha}$. Menurut penelitian yang dilakukan oleh (Suryatmojo, 2011 dalam Muttaqin, 2018) ) erosi tanah rata-rata di hutan hujan tropis alami Kalimantan Tengah adalah 10,01 kg/ha.

Berdasarkan hasil penelitian Suryatmojo, hasil yang didapatkan pada lahan rehabilitasi bekas kebakaran Tahura R.Soerjo Blok Ledug ini termasuk rendah. Dimana hasil yang didapatkan yaitu rataratanya $0,48 \mathrm{~kg} / \mathrm{ha}$. Hal ini menunjukkan bahwa sedimen yang terangkut oleh air jumlahnya tidak banyak dan rendah. Rendahnya sedimen yang terangkut ini juga dipengaruhi oleh kondisi vegetasi yang ada pada kawasan tersebut. Kondisi vegetasi yang terdapat pada lahan tersebut yaitu didominasi oleh ilalang yang cukup tinggi, dimana vegetasi dapat membantu dalam menahan gempuran air hujan agar tidak langsung menggerus atau mengikis lapisan permukaan tanah sehingga sedimen yang ikut terangkut oleh air juga sedikit. Pengangkutan sedimen oleh air tidak bisa dihindari, namun jika kawasan tersebut memiliki vegetasi yang cukup banyak dan mampu menahan air yang melewati kawasan tersebut, maka akan bisa dipastikan jika erosi ataupun pengikisan tanah yang terjadi pada lahan tersebut akan rendah.

\section{Kesimpulan}

Didapatkan 13 kejadian hujan yang terjadi pada bulan Desember 2018 dan 13 hidrograf aliran dan hidrograf suspensi untuk menduga sedimentasi yang terjadi.

Curah hujan tertinggi yaitu 68,2 $\mathrm{mm}$, dan curah hujan terendah yaitu 2,5 $\mathrm{mm}$. Diperoleh persamaan QS = $0,7707(\mathrm{Q}) 0,8803$ dengan nilai $R^{2}=0,2419$ dimana QS yaitu debit suspensi $(\mathrm{kg} / \mathrm{s})$ dan Q adalah debit aliran $(\mathrm{m} 3 / \mathrm{s}) . \quad R^{2}$ menunjukkan seberapa besar pengaruh variabel $X$ terhadap variabel $Y$, sebesar $24,19 \%$.

sedimen yang terjadi termasuk rendah yaitu rata-rata $0,48 \mathrm{~kg} / \mathrm{ha}$. Rendahnya nilai sedimentasi yang didapatkan dipengaruhi oleh kondisi kawasan yang memiliki vegetasi yang rapat dan didominasi oleh ilalang.

\section{Saran}

Adapun saran yang dapat diberikan kepada pihak TAHURA yaitu Agar melakukan kegiatan rehabilitasi berdasarkan dengan hasil penelitian yang sudah dilakukan. Kegiatan rehabilitasi yang dapat dilakukan yaitu penanaman. Serta pihak TAHURA dapat memberikan sosialisasi atau penyuluhan kepada masyarakat sekitar hutan agar kebakaran lahan tidak terjadi lagi di waktu yang akan datang.

\section{Daftar Pustaka}




\section{JOURNAL OF FOREST SCIENCE AVICENNIA}

E-ISSN : 2622-8505 | Email : avicennia kehutananummioumm.ac id htip//cjournal umm ac.it/index.php/avicennia

II. Faya Tlogomas No.246 Malang Jawa Timur $(0822-5785-2386$ (Febri)

Murtinah, V., Edwin, M. and Bane, O. (2017) 'Dampak Kebakaran Hutan Terhadap Sifat Fisik dan Kimia Tanah di Taman Nasional Kutai , Kalimantan Timur', (01), pp. 128-139.

Muttaqin, T. (2018) Laju Erosi Di Lahan Rehabilitasi Bekas Kebakaran Kawasan Taman Hutan Raya R.Soeryo Jawa Timur. Universitas Muhammadiyah Malang.

Soewarno, 2000. Hidrologi Operasional. PT. Citra Aditya Bakti. Bandung.

Undang-Undang Republik Indonesia Nomor 41 Tahun 1999 tentang Kehutanan. 